\title{
Practical Research on Physical Rehabilitation Training among Male Addicts in Chinese Compulsory Isolated Detoxification Center
}

\author{
Dongming Jia ${ }^{*}$, Zhifei $\mathrm{Xu}^{2}$, Song Guo ${ }^{3}$, Yang Shen ${ }^{4}$ \\ ${ }^{1}$ Department of Criminal Justice, Zhejiang Police Vocational Academy, Hangzhou, China \\ ${ }^{2}$ Department of Information Management, Zhejiang Police Vocational Academy, Hangzhou, China \\ ${ }^{3}$ Department of Education and Correction, Zhejiang Gongchen Compulsory Isolated Detoxification Center, Hangzhou, China \\ ${ }^{4}$ Department of Medical Rehabilitation, Zhejiang Detoxification Administration, Hangzhou, China \\ Email: *jiadm1@126.com
}

How to cite this paper: Jia, D.M., Xu, Z.F. Guo, S. and Shen, Y. (2018) Practical Research on Physical Rehabilitation Training among Male Addicts in Chinese Compulsory Isolated Detoxification Center. Open Journal of Preventive Medicine, 8, 121-130. https://doi.org/10.4236/ojpm.2018.84012

Received: March 16, 2018

Accepted: April 23, 2018

Published: April 26, 2018

Copyright (c) 2018 by authors and Scientific Research Publishing Inc. This work is licensed under the Creative Commons Attribution International License (CC BY 4.0).

http://creativecommons.org/licenses/by/4.0/

\begin{abstract}
Background: Physical rehabilitation training as an effective measure was proposed by relevant government sector recently. Many compulsory isolated detoxification centers had already implemented the measure, but rarely a systematically comprehensive research was published. Therefore, the purpose of this paper was to evaluate the effect of " 5433 " training program as an exercise intervention on addicts during drug treatment and rehabilitation, in order to provide the experimental data for the research about the effects of mental quality and physical quality of addicts. Methods. The 2132 male addicts were randomly divided into experimental group $(\mathrm{n}=1020)$ and control group $(\mathrm{n}=$ 1112), experimental group was training by “5433" program, and control group ordinary was managed alone. Before and after one year training, in accordance with the "SCL-90" and "Standards of People's Republic of China national physique", the SCL-90 scores, height/weight, vital capacity, step index, grip strength, vertical jump, push-ups, sit-and-reach, one-leg standing with eye-closed, choice reaction index of two groups were detected. Results. 1) The scores of depression, anxiety, paranoia and psychosis in two groups before the experiment are both lower than those after the experiment, and the experimental group decreased more $(\mathrm{P}<0.05)$. There were no differences in the scores of somatization and phobias between groups. 2) There has a significant difference between the number of qualified and the unqualified addicts in the experimental group compared to one year ago $(\mathrm{P}<0.05)$. Each single term index proportion of height/weight, vital capacity, step index, vertical jump, push-ups, sit-and-reach, one-leg standing with eye-closed and choice reaction index has significant statistical difference on the number of qualified and un-
\end{abstract}


qualified addicts in the experimental group before and after one year's training $(\mathrm{P}<0.05)$, but grip strength index proportion has not $(\mathrm{P}>0.05)$. Conclusion: These initial findings show that The "5433" Training Program was effective more than a simple kinesiotherapy, thereby opening avenues for the rehabilitation of Chinese drug addicts.

\section{Keywords}

Physical Rehabilitation, Addicts, Compulsory Isolated Detoxification, China

\section{Introduction}

The process of drug addiction is related to many factors, such as physiological, psychological, sociological and spiritual, and so on. Now available psychosomatic rehabilitation protocols are far from satisfying because of poor therapeutic efficiency or abstention rate [1]. "Physical rehabilitation" is a major indicator of the treatment effects. Physical rehabilitation training is an important part of drug abstinence work in Chinese Compulsory Isolated Detoxification Centers, which plays an elementary role in promoting the physical and mental health of the addicts and helping them to abstain from drug addiction, according to Ministry of Justice of China [2].

At present, there has been plenty of research on the mental rehabilitation of addicts in China [3]. Yet, it is rather weak in the research of addict on their psychosomatic rehabilitation from physical rehabilitation [4]. This article presents preliminary results from the " 5433 " training program of 2132 male addicts in Zhejiang Gongchen Compulsory Isolated Detoxification Center [5].

In "5433" Training Program, 5 means: 1) work-break exercises once per half day; 2) outdoor rehabilitation training one hour per day; 3) indoor equipment training once per week; 4) check and evaluate once per month; 5) achievement exhibition once per half year. 4 means: 1) "slow motion" in Physiological detoxification ward, such as outdoor walking and joint exercises etc.; 2) "teaching operation" in Educational adjustment ward, consisted of drill regulation, setting up exercises to radio music, Taijiquan skills and basic motion theory [6]; 3) "aerobic exercise" in Consolidation ward, carry out strength, endurance, flexibility, balance training, such as aerobics, equipment training, and so on; 4) "fun sport" in Reintegration guidance ward, involves group calisthenics and outward bound. 3 means three test at three time points: 1) admitted;2) expiration of 1 year; 3 ) disisolation. And the last 3 means three tutor sites from social support [7]: 1) National Physique Measurement; 2) Martial Arts Association; 3) Asian Sports and Physical Fitness Institute.

\section{Methods}

\subsection{Study Design}

The male addicts are selected from Zhejiang Gongchen Compulsory Isolated 
Detoxification Center (February 2015 to March 2016), and randomly divided into two groups (experimental group and control group). The experimental group followed " 5433 " training program as played in Figure 1, the control group engaged in ordinary management alone, and both groups experience four periods in four different wards (Physiological detoxification ward, Educational adjustment ward, Consolidation ward and Reintegration guidance ward) in 1 year. Both groups' indicator of mental quality and physical quality will be test before and after 12 months, and the tested items are compared with the Symptom Checklist 90 (SCL-90) scores and Standards of People's Republic of China national physique [5].

Data (Test 1 and Test 3 as appropriate) acquisition is derived from questionnaire, literature review and instrument from the first 12 months. The test instrument is National Physique Tester (Ogilvy road Ver8.0, Jian Min Limited). The two sets of data are analyzed statistically within and between groups.

\subsection{Study Population}

The target population for the study was male addicts at the Zhejiang Gongchen Compulsory Isolated Detoxification Center. The inclusion criteria were: 1) in line with the Chinese classification of mental disorders and diagnostic criteria (CCMD-3) [8], and no history of mental illness in the past [9]; 2) age was 20 $40 ; 3)$ have no physical disability; no history of hypertension, diabetes and other chronic diseases; 4) the ability to understand, communicate and write in a normal language; 5) volunteered to participate in this research.

The study was approved by ethics committee and written informed consent forms were obtained from all subjects. The sample size were determined by statistical treatment, the minimum sample content in the test of mean number difference was 264, and 470 in nonparametric test of percentages ( $\alpha=0.05, \beta=0.1)$. Actually, 2132 subjects were participated in the study.

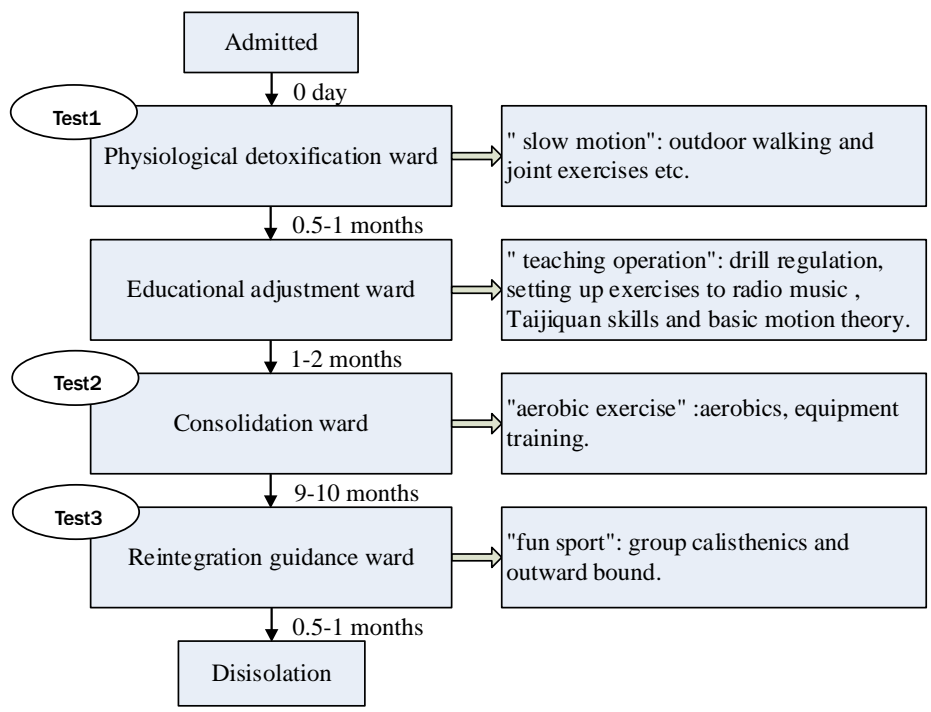

Figure 1. Flowchart of “5433” training program. 


\subsection{Variables Recorded}

Psychological scales: Computerized self-report questionnaire of SCL-90 was required to finish in 30 minutes according to actual situation, symptom factors consist of somatization, obsessive compulsive symptoms, interpersonal relationships, depression, anxiety, hostility, phobias, paranoia, psychosis etc [10].

Physiological indexes: The National Physique Tester recorded 10 indicators covered the data of comprehensive physique rating, height/weight, vital capacity, step index, grip strength, vertical jump, push-ups, sit-and-reach, one-leg standing with eye-closed and choice reaction index [11].

\subsection{Statistical Analysis}

Descriptive analysis of all available data was performed. Quantitative data are described as mean \pm standard deviation and qualitative variables as number. Using paired $\mathrm{T}$ test to analyze the psychological scales before and after the same sample experiment, and independent sample $\mathrm{T}$ test to analyze the differences between the two groups before and after the experiment. Percentages of physiological indexes were compared by nonparametric test, compared with the count data using Pearson Chi-square test. Results of the analysis are presented as odds ratios (OR) and $95 \%$ confidence interval (95\% CI). A P-value $<0.05$ was considered statistically significant. All analyses were performed using SPSS version19.0 (SPSS Inc. Chicago, IL, USA).

\section{Results}

In total, 2132 subjects were participated, and randomly divided into experimental group (1020 cases) and control group (1112 cases), average age $29.7 \pm 5.15$ year, there was no significant difference of age between two groups $(t=2.143$, $\mathrm{P}>0.05)$.

\subsection{Psychological Scales}

\subsubsection{Comparison of Evaluation Results between the Addicts and Norm} There is no important difference in each factor of the two groups before the experiment $(P>0.05)$. Significant difference was observed for the scores of coercion, interpersonal relations, depression, anxiety, hostility, paranoia and psychosis between each group and Chinese norm $(\mathrm{P}<0.05, \mathrm{P}<0.05$ respectively); but the scores of somatization and phobias was not observed $(\mathrm{P}>0.05, \mathrm{P}>0.05$ respectively) (Table 1).

\subsubsection{Comparison of Evaluation Results between the Experimental Group and the Control Group}

The scores of depression, anxiety, paranoia and psychosis in two groups before the experiment are both lower than those after the experiment, and the experimental group decreased more $(\mathrm{P}<0.05)$. The scores of hostility, coercion and interpersonal relations had a significant reduction in the experimental group after the experiment $(\mathrm{P}<0.05)$, but no reduction in control group. There were no 
differences in the scores of somatization and phobias between groups (Table 2).

\subsection{Physiological Indexes}

\subsubsection{Comparison of Physique Comprehensive Rating}

The two groups of physical comprehensive rating data were carried out by Pearson's chi-squared test. There has a significant difference between the number of qualified and the unqualified addicts in the experimental group compared to one year ago $(P<0.05)$. Meanwhile, there were significant differences on the number of qualified and unqualified addicts between the experimental group and the control group after one year $(\mathrm{P}<0.05)$. No significant differences were showed in the number of qualified and unqualified addicts in the control group $(\mathrm{P}>$ $0.05)$, and between the experimental group and the control group one year ago $(\mathrm{P}>0.05)$ (Table 3).

Table 1. Comparison of evaluation results between the addicts and norm.

\begin{tabular}{|c|c|c|c|c|c|c|}
\hline \multirow{2}{*}{ Factor } & \multirow{2}{*}{$\begin{array}{c}\left.{ }^{\mathrm{a}} 1\right) \text { Experimental } \\
\text { group } \\
(\mathrm{n}=1020)\end{array}$} & \multirow{2}{*}{$\begin{array}{l}\text { a2) Control } \\
\text { group } \\
(n=1112)\end{array}$} & \multirow{2}{*}{$\begin{array}{l}\text { 3) Chinese Norm } \\
(\mathrm{n}=1890)\end{array}$} & \multicolumn{3}{|c|}{$\mathrm{P}$} \\
\hline & & & & 1) 2) & 1) 3) & 2) 3) \\
\hline Somatization & $1.40 \pm 0.35$ & $1.41 \pm 0.24$ & $1.37 \pm 0.48$ & 0.382 & 0.363 & 0.310 \\
\hline Coercion & $2.12 \pm 0.29$ & $2.13 \pm 0.21$ & $1.62 \pm 0.58$ & 0.712 & 0.003 & 0.001 \\
\hline Interpersonal & $1.96 \pm 0.31$ & $1.97 \pm 0.17$ & $1.65 \pm 0.51$ & 0.405 & 0.012 & 0.014 \\
\hline \multicolumn{7}{|l|}{ Relations } \\
\hline Depression & $2.18 \pm 0.33$ & $2.17 \pm 0.29$ & $1.50 \pm 0.59$ & 0.810 & 0.000 & 0.000 \\
\hline Anxiety & $2.04 \pm 0.30$ & $2.05 \pm 0.22$ & $1.39 \pm 0.43$ & 0.603 & 0.000 & 0.000 \\
\hline Hostility & $1.93 \pm 0.28$ & $1.91 \pm 0.32$ & $1.48 \pm 0.56$ & 0.592 & 0.031 & 0.029 \\
\hline Phobias & $1.28 \pm 0.18$ & $1.27 \pm 0.26$ & $1.23 \pm 0.41$ & 0.704 & 0.572 & 0.534 \\
\hline Paranoia & $1.89 \pm 0.28$ & $1.88 \pm 0.26$ & $1.43 \pm 0.57$ & 0.672 & 0.028 & 0.031 \\
\hline Psychosis & $1.82 \pm 0.21$ & $1.81 \pm 0.32$ & $1.29 \pm 0.42$ & 0.877 & 0.011 & 0.015 \\
\hline
\end{tabular}

before 1 year.

Table 2. Comparison of evaluation results between the two groups.

\begin{tabular}{|c|c|c|c|c|c|c|c|}
\hline \multirow[t]{2}{*}{ Factor } & \multicolumn{2}{|c|}{$\begin{array}{l}\text { Experimental group } \\
\qquad(\mathrm{n}=1020)\end{array}$} & \multicolumn{2}{|c|}{$\begin{array}{l}\text { Control group } \\
(\mathrm{n}=1112)\end{array}$} & \multicolumn{3}{|c|}{$\mathrm{P}$} \\
\hline & $\left.{ }^{\mathrm{a}} 1\right)$ & $\left.{ }^{b} 2\right)$ & a3) & $\left.{ }^{\mathrm{b}} 4\right)$ & 1) 2) & 3) 4) & 2) 4) \\
\hline Somatization & $1.40 \pm 0.35$ & $1.38 \pm 0.32$ & $1.41 \pm 0.24$ & $1.37 \pm 0.11$ & 0.716 & 0.363 & 0.871 \\
\hline Coercion & $2.12 \pm 0.29$ & $1.63 \pm 0.46$ & $2.13 \pm 0.21$ & $1.86 \pm 0.29$ & 0.027 & 0.227 & 0.042 \\
\hline $\begin{array}{c}\text { Interpersonal } \\
\text { Relations }\end{array}$ & $1.96 \pm 0.31$ & $1.64 \pm 0.35$ & $1.97 \pm 0.17$ & $1.89 \pm 0.36$ & 0.032 & 0.102 & 0.037 \\
\hline Depression & $2.18 \pm 0.33$ & $1.52 \pm 0.36$ & $2.17 \pm 0.29$ & $1.54 \pm 0.28$ & 0.003 & 0.012 & 0.776 \\
\hline Anxiety & $2.04 \pm 0.30$ & $1.41 \pm 0.32$ & $2.05 \pm 0.22$ & $1.43 \pm 0.27$ & 0.000 & 0.006 & 0.760 \\
\hline Hostility & $1.93 \pm 0.28$ & $1.47 \pm 0.42$ & $1.91 \pm 0.32$ & $1.85 \pm 0.31$ & 0.007 & 0.402 & 0.019 \\
\hline Phobias & $1.28 \pm 0.18$ & $1.27 \pm 0.37$ & $1.27 \pm 0.26$ & $1.28 \pm 0.20$ & 0.891 & 0.774 & 0.823 \\
\hline Paranoia & $1.89 \pm 0.28$ & $1.45 \pm 0.41$ & $1.88 \pm 0.26$ & $1.46 \pm 0.26$ & 0.017 & 0.339 & 0.021 \\
\hline Psychosis & $1.82 \pm 0.21$ & $1.31 \pm 0.39$ & $1.81 \pm 0.32$ & $1.32 \pm 0.32$ & 0.012 & 0.032 & 0.014 \\
\hline
\end{tabular}

abefore 1 year; ${ }^{\text {bafter }} 1$ year. 
Table 3. Comparison of comprehensive physique rating of two groups before and after 1 year.

\begin{tabular}{|c|c|c|c|c|c|c|c|c|}
\hline \multirow{2}{*}{$\begin{array}{l}\text { Comprehensive } \\
\text { physique rating }\end{array}$} & \multicolumn{2}{|c|}{$\begin{array}{l}\text { Experimental group } \\
\qquad(\mathrm{n}=1020)\end{array}$} & \multirow{2}{*}{$x^{2}$} & \multicolumn{2}{|c|}{$\begin{array}{l}\text { Control group } \\
\quad(\mathrm{n}=1112)\end{array}$} & \multirow{2}{*}{$x^{2}$} & \multicolumn{2}{|c|}{$x^{2}$} \\
\hline & $\left.{ }^{\mathrm{a}} 1\right)$ & $\left.{ }^{b} 2\right)$ & & a3) & $\left.{ }^{\mathrm{b}} 4\right)$ & & 1) 3$)$ & 2) 4) \\
\hline Qualified & 849 & 889 & \multirow{2}{*}{$6.219^{*}$} & 924 & 926 & \multirow{2}{*}{0.013} & \multirow{2}{*}{0.008} & \multirow[b]{2}{*}{$6.339^{\star}$} \\
\hline Unqualified & 171 & 131 & & 188 & 186 & & & \\
\hline
\end{tabular}

abefore 1 year; ${ }^{\text {bafter } 1}$ year; ${ }^{\star} \mathrm{P}<0.05$.

\subsubsection{Comparison of the of Single Term Index Proportion}

Each single term index proportion of height/weight, vital capacity, step index, vertical jump, push-ups, sit-and-reach, one-leg standing with eye-closed and choice reaction index has significant statistical difference on the number of qualified and unqualified addicts in the experimental group before and after one year's training $(\mathrm{P}<0.05)$, but grip strength index proportion has not $(\mathrm{P}>0.05)$. Each single term index proportion of height/weight, vital capacity, step index, one-leg standing with eye-closed, choice reaction index has significant statistical difference on the number of qualified and unqualified addicts between the experimental group and the control group $(\mathrm{P}<0.05)$, but grip strength, vertical jump and push-ups index proportion have not $(\mathrm{P}>0.05)$ (Tables 4-12).

\section{Discussion}

\subsection{Influence of "5433" Training Program on the Addicts' Psychology}

Compared with the national norm, there was no significant difference in the both groups' SCL-90 scores from both groups before the experiment except the scores of somatization and phobias. In the study, no significant differences were found in SCL-90 scores between the experimental group and the control group before the experiment.

Through a year of training, the scores of depression, anxiety, paranoia and psychosis factor were lower than that before the experiment with significant differences, and the scores of hostility, coercion and interpersonal relationship had greatly decreased in the experimental group specially. The results showed that long training can better assist the rehabilitation of drug addicts and improve their mental health and psychological states [12].

\subsection{Influence of “5433" Training Program on the Addicts' Physiology}

After one year of training, the number of qualified persons increased significantly ( 889 vs 849 ) in accordance with comprehensive physique rating.

The single index can further reflect the harm to respiratory, nervous and cardiovascular systems; for instance, vital capacity index can reflect the impact caused by drugs on respiratory system; grip, push-ups can reflect the power quality; vertical jump, one-leg standing with eye-closed and choice reaction index 
Table 4. Comparison of height/weight index proportion of two groups before and after 1 year.

\begin{tabular}{|c|c|c|c|c|c|c|c|c|}
\hline \multirow[t]{2}{*}{ Height/Weight } & \multicolumn{2}{|c|}{$\begin{array}{l}\text { Experimental group } \\
\qquad(\mathrm{n}=1020)\end{array}$} & \multirow{2}{*}{$x^{2}$} & \multicolumn{2}{|c|}{$\begin{array}{l}\text { Control group } \\
(\mathrm{n}=1112)\end{array}$} & \multirow{2}{*}{$x^{2}$} & \multicolumn{2}{|c|}{$x^{2}$} \\
\hline & $\left.{ }^{\mathrm{a}} 1\right)$ & $\left.\mathrm{b}_{2}\right)$ & & a) & $\left.{ }^{b} 4\right)$ & & 1) 3) & 2) 4) \\
\hline Qualified & 834 & 874 & \multirow[b]{2}{*}{$5.756^{*}$} & 906 & 896 & \multirow[b]{2}{*}{0.292} & \multirow[b]{2}{*}{0.030} & \multirow[b]{2}{*}{$9.858^{\times}$} \\
\hline Unqualified & 186 & 146 & & 206 & 216 & & & \\
\hline
\end{tabular}

${ }^{\mathrm{a}}$ before 1 year; ${ }^{\mathrm{b}}$ after 1 year; ${ }^{*} \mathrm{P}<0.05$.

Table 5. Comparison of vital capacity index proportion of two groups before and after 1 year.

\begin{tabular}{|c|c|c|c|c|c|c|c|c|}
\hline \multirow{2}{*}{ Vital capacity } & \multicolumn{2}{|c|}{$\begin{array}{l}\text { Experimental group } \\
\quad(\mathrm{n}=1020)\end{array}$} & \multirow{2}{*}{$x^{2}$} & \multicolumn{2}{|c|}{$\begin{array}{l}\text { Control group } \\
\quad(\mathrm{n}=1112)\end{array}$} & \multirow{2}{*}{$x^{2}$} & \multicolumn{2}{|c|}{$x^{2}$} \\
\hline & $\left.{ }^{\mathrm{a}} 1\right)$ & $\left.{ }^{b} 2\right)$ & & a) & $\left.{ }^{\mathrm{b}} 4\right)$ & & 1) 3) & 2) 4) \\
\hline Qualified & 325 & 384 & & 308 & 316 & & & \\
\hline Unqualified & 695 & 636 & $7.525^{\star}$ & 804 & 796 & 0.143 & 0.442 & $20.551^{\star}$ \\
\hline
\end{tabular}

${ }^{\mathrm{a}}$ before 1 year; ${ }^{\mathrm{b}}$ after 1 year; ${ }^{*} \mathrm{P}<0.05$.

Table 6. Comparison of step index proportion of two groups before and after 1 year.

\begin{tabular}{|c|c|c|c|c|c|c|c|c|}
\hline \multirow[t]{2}{*}{ Step index } & \multicolumn{2}{|c|}{$\begin{array}{l}\text { Experimental group } \\
\qquad(\mathrm{n}=1020)\end{array}$} & \multirow{2}{*}{$x^{2}$} & \multicolumn{2}{|c|}{$\begin{array}{l}\text { Control group } \\
\quad(\mathrm{n}=1112)\end{array}$} & \multirow{2}{*}{$x^{2}$} & \multicolumn{2}{|c|}{$x^{2}$} \\
\hline & $\left.{ }^{\mathrm{a}} 1\right)$ & $\left.{ }^{b} 2\right)$ & & a) & $\left.{ }^{b} 4\right)$ & & 1) 3$)$ & 2) 4) \\
\hline Qualified & 861 & 911 & \multirow[b]{2}{*}{$10.739^{*}$} & 920 & 926 & \multirow[b]{2}{*}{0.115} & \multirow[b]{2}{*}{1.089} & \multirow[b]{2}{*}{$16.281^{\star}$} \\
\hline Unqualified & 159 & 109 & & 192 & 186 & & & \\
\hline
\end{tabular}

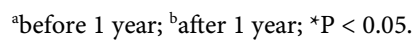

Table 7. Comparison of grip strength index proportion of two groups before and after 1 year.

\begin{tabular}{|c|c|c|c|c|c|c|c|c|}
\hline \multirow{2}{*}{ Grip strength } & \multicolumn{2}{|c|}{$\begin{array}{l}\text { Experimental group } \\
\qquad(\mathrm{n}=1020)\end{array}$} & \multirow{2}{*}{$x^{2}$} & \multicolumn{2}{|c|}{$\begin{array}{l}\text { Control group } \\
(\mathrm{n}=1112)\end{array}$} & \multirow{2}{*}{$x^{2}$} & \multicolumn{2}{|c|}{$x^{2}$} \\
\hline & $\left.{ }^{\mathrm{a}} 1\right)$ & $\left.{ }^{b} 2\right)$ & & a3) & $\left.{ }^{\mathrm{b}} 4\right)$ & & 1) 3) & 2) 4) \\
\hline Qualified & 414 & 449 & & 450 & 469 & & & \\
\hline Unqualified & 606 & 571 & 2.460 & 662 & 643 & 0.669 & 0.003 & 0.737 \\
\hline
\end{tabular}

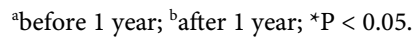

Table 8. Comparison of vertical jump index proportion of two groups before and after 1 year.

\begin{tabular}{|c|c|c|c|c|c|c|c|c|}
\hline \multirow{2}{*}{ Vertical jump } & \multicolumn{2}{|c|}{$\begin{array}{l}\text { Experimental group } \\
\qquad(\mathrm{n}=1020)\end{array}$} & \multirow{2}{*}{$x^{2}$} & \multicolumn{2}{|c|}{$\begin{array}{l}\text { Control group } \\
\quad(\mathrm{n}=1112)\end{array}$} & \multirow{2}{*}{$x^{2}$} & \multicolumn{2}{|c|}{$x^{2}$} \\
\hline & $\left.{ }^{\mathrm{a}} 1\right)$ & $\left.{ }^{b} 2\right)$ & & a3) & $\left.{ }^{\mathrm{b}} 4\right)$ & & 1) 3$)$ & 2) 4) \\
\hline Qualified & 456 & 513 & \multirow[b]{2}{*}{$6.387^{\star}$} & 500 & 514 & \multirow[b]{2}{*}{0.355} & \multirow[b]{2}{*}{0.014} & \multirow[b]{2}{*}{3.532} \\
\hline Unqualified & 564 & 507 & & 612 & 598 & & & \\
\hline
\end{tabular}

abefore 1 year; ${ }^{\mathrm{b}}$ after 1 year; ${ }^{\star} \mathrm{P}<0.05$. 
Table 9. Comparison of push-ups index proportion of two groups before and after 1 year.

\begin{tabular}{|c|c|c|c|c|c|c|c|c|}
\hline \multirow{2}{*}{ Push-ups } & \multicolumn{2}{|c|}{$\begin{array}{l}\text { Experimental group } \\
\qquad(\mathrm{n}=1020)\end{array}$} & \multirow{2}{*}{$x^{2}$} & \multicolumn{2}{|c|}{$\begin{array}{l}\text { Control group } \\
(\mathrm{n}=1112)\end{array}$} & \multirow{2}{*}{$x^{2}$} & \multicolumn{2}{|c|}{$x^{2}$} \\
\hline & $\left.{ }^{\mathrm{a}} 1\right)$ & $\left.{ }^{b} 2\right)$ & & a3) & $\left.{ }^{b} 4\right)$ & & 1) 3$)$ & 2) 4) \\
\hline Qualified & 602 & 646 & \multirow{2}{*}{$3.996^{*}$} & 659 & 668 & \multirow{2}{*}{0.151} & \multirow{2}{*}{0.013} & \multirow{2}{*}{2.393} \\
\hline Unqualified & 418 & 374 & & 453 & 444 & & & \\
\hline
\end{tabular}

${ }^{a}$ before 1 year; ${ }^{b}$ after 1 year; ${ }^{*} \mathrm{P}<0.05$.

Table 10. Comparison of sit-and-reach index proportion of two groups before and after 1 year.

\begin{tabular}{|c|c|c|c|c|c|c|c|c|}
\hline \multirow{2}{*}{ Sit-and-reach } & \multicolumn{2}{|c|}{$\begin{array}{l}\text { Experimental group } \\
\qquad(\mathrm{n}=1020)\end{array}$} & \multirow{2}{*}{$x^{2}$} & \multicolumn{2}{|c|}{$\begin{array}{l}\text { Control group } \\
(\mathrm{n}=1112)\end{array}$} & \multirow{2}{*}{$x^{2}$} & \multicolumn{2}{|c|}{$x^{2}$} \\
\hline & $\left.{ }^{\mathrm{a}} 1\right)$ & $\left.{ }^{b} 2\right)$ & & a) & $\left.{ }^{\mathrm{b}} 4\right)$ & & 1) 3$)$ & 2) 4) \\
\hline Qualified & 635 & 707 & \multirow{2}{*}{$11.290^{*}$} & 695 & 700 & \multirow{2}{*}{0.048} & \multirow{2}{*}{0.014} & \multirow{2}{*}{$9.601^{\times}$} \\
\hline Unqualified & 385 & 313 & & 417 & 412 & & & \\
\hline
\end{tabular}

abefore 1 year; ${ }^{\text {bafter } 1}$ year; ${ }^{\star} \mathrm{P}<0.05$.

Table 11. Comparison of one-leg standing with eye-closed index proportion of two groups before and after 1 year.

\begin{tabular}{|c|c|c|c|c|c|c|c|c|}
\hline \multirow{2}{*}{$\begin{array}{l}\text { One-leg standing } \\
\text { with eye-closed }\end{array}$} & \multicolumn{2}{|c|}{$\begin{array}{l}\text { Experimental group } \\
\qquad(\mathrm{n}=1020)\end{array}$} & \multirow{2}{*}{$x^{2}$} & \multicolumn{2}{|c|}{$\begin{array}{l}\text { Control group } \\
(\mathrm{n}=1112)\end{array}$} & \multirow[t]{2}{*}{$x^{2}$} & \multicolumn{2}{|c|}{$x^{2}$} \\
\hline & $\left.{ }^{\mathrm{a}} 1\right)$ & $\left.{ }^{b} 2\right)$ & & a) & $\left.{ }^{\mathrm{b}} 4\right)$ & & 1) 3) & 2) 4) \\
\hline Qualified & 551 & 668 & \multirow{2}{*}{$27.903^{\star}$} & 602 & 627 & \multirow{2}{*}{1.137} & \multirow{2}{*}{0.003} & \multirow{2}{*}{$18.496^{`}$} \\
\hline Unqualified & 469 & 352 & & 510 & 485 & & & \\
\hline
\end{tabular}

abefore 1 year; ${ }^{b}$ after 1 year; ${ }^{*} \mathrm{P}<0.05$.

Table 12. Comparison of choice reaction index proportion of two groups before and after 1 year.

\begin{tabular}{|c|c|c|c|c|c|c|c|c|}
\hline \multirow{2}{*}{$\begin{array}{l}\text { Choice reaction } \\
\text { index }\end{array}$} & \multicolumn{2}{|c|}{$\begin{array}{l}\text { Experimental group } \\
\qquad(\mathrm{n}=1020)\end{array}$} & \multirow{2}{*}{$x^{2}$} & \multicolumn{2}{|c|}{$\begin{array}{l}\text { Control group } \\
(\mathrm{n}=1112)\end{array}$} & \multirow{2}{*}{$x^{2}$} & \multicolumn{2}{|c|}{$x^{2}$} \\
\hline & $\left.{ }^{\mathrm{a}} 1\right)$ & $\left.{ }^{\mathrm{b}} 2\right)$ & & a) & $\left.{ }^{\mathrm{b}} 4\right)$ & & 1) 3$)$ & 2) 4) \\
\hline Qualified & 876 & 929 & \multirow{2}{*}{$13.509^{*}$} & 956 & 983 & \multirow{2}{*}{2.934} & \multirow{2}{*}{0.003} & \multirow{2}{*}{$4.126^{*}$} \\
\hline Unqualified & 144 & 91 & & 156 & 129 & & & \\
\hline
\end{tabular}

abefore 1 year; ${ }^{\mathrm{b}}$ after 1 year; ${ }^{*} \mathrm{P}<0.05$.

can reflect injury to autonomic nervous system caused by synthetic drugs [13], especially.

The indicators of height/weight, vital capacity, step index, sit-and-reach, one-leg standing with eye-closed and choice reaction index increased obviously; however, not for grip strength, vertical jump and push-ups. That may result from the addicts' poor physical power as long-term drug abuse, and is difficult to recovery in short period [14]. The "5433" training program was effective.

\subsection{Limitations of the Study}

The training program lasted for only more than one year, data nodes were col- 
lected before and after a year. We should continue to adjust the training methods and time span to evaluate long term effect of rehabilitation. As there has been lack of special study on female addicts, a further study is needed to examine and extend the research.

\section{Conclusion}

The "5433" Training Program was effective more than a simple kinesiotherapy [15]. It contains a series of integrated methods, such as indoor equipment training, Tai Chi and social support. It is a promising way to restore and improve the psychological and physiological functions of drug addicts along with professional rehabilitation measures for drug addicts.

\section{Acknowledgements}

The authors thank the members of the Zhejiang Police Vocational Academy and Zhejiang Gongchen Compulsory Isolated Detoxification Center who made this project possible. This project was supported by grants from the Industry Service Promotion Program of Zhejiang Police Vocational Academy (JY20170204).

\section{References}

[1] Wise, R.A. and Koob, G.F. (2014) The Development and Maintenance of Drug Addiction. Neuropsychopharmacology, 39, 254. https://doi.org/10.1038/npp.2013.261

[2] Liu, Z.Y. (2013) Preliminary Exploration on the Value Function and Realization Path of Compulsory Isolation and Detoxification of Judicial Administration in Strengthening and Innovating Social Management. China's Judicature, No. 1, 69-75.

[3] Yu, L., Liang, J., Zhao, C. and Zhou, W. (2010) Looking for a Solution for Drug Addiction in China: Exploring the Challenges and opportunities in the Way of China's New Drug Control Law. International Journal of Drug Policy, 21, 149-154. https://doi.org/10.1016/j.drugpo.2009.10.002

[4] Chen, F.C. (2011) Value and Function of Physical Ability Rehabilitation Training. Sports Scientific Research, 32, 27-29.

[5] Jia, D.M. and Guo, S. (2016) Practical Research on Physical Rehabilitation Training of the Male Compulsory Isolation Addicts in Zhejiang Province. Bulletin of Sport Science \& Technology, 24, 22-24.

[6] Zou, L. (2017) Taichi Softball as a Novel Chinese Health-Promoting Exercise for Physical Health: A Systematic Review and Meta-Analysis. Open Journal of Preventive Medicine, 7, 15-31. https://doi.org/10.4236/ojpm.2017.72002

[7] Aklin, W.M., Wong, C.J., Hampton, J., Svikis, D.S., Stitzer, M.L., Bigelow, G.E., et al. (2014) A Therapeutic Workplace for the Long-Term Treatment of Drug Addiction and Unemployment: Eight-Year Outcomes of a Social Business Intervention. Journal of Substance Abuse Treatment, 47, 329-338. https://doi.org/10.1016/j.jsat.2014.06.013

[8] Chen, Y.F. (2002) Chinese Classification of Mental Disorders (ccmd-3): Towards Integration in International Classification. Psychopathology, 35, 171. https://doi.org/10.1159/000065140

[9] Hong, Y., Li, J.X. and Robinson, P. (2000) Balance Control, Flexibility, and Cardiorespiratory Fitness among Older Tai Chi Practitioners. British Journal of Sports 
Medicine, 34, 29. https://doi.org/10.1136/bjsm.34.1.29

[10] Baharudin, D.F., Hussin, A.H.M., Sumari, M., Mohamed, S., Zakaria, M.Z. and Sawai, R.P. (2014) Family Intervention for the Treatment and Rehabilitation of Drug Addiction: An Exploratory Study. Journal of Substance Use, 19, 301-306. https://doi.org/10.3109/14659891.2013.799239

[11] Bellamoli, E., Manganotti, P., Schwartz, R.P., Rimondo, C., Gomma, M. and Serpelloni, G. (2014) rTMS in the Treatment of Drug Addiction: An Update about Human Studies. Behavioural Neurology, 2014, Article ID: 815215. https://doi.org/10.1155/2014/815215

[12] Spagnolo, P.A., Colloca, L. and Heilig, M. (2015) The Role of Expectation in the Therapeutic Outcomes of Alcohol and Drug Addiction Treatments. Alcohol \& Alcoholism, 50, 282-285. https://doi.org/10.1093/alcalc/agv015

[13] Jia, D.M. and Guo, S. (2015) Construction of Compulsory Isolation Detoxification in Physical Rehabilitation Work Procedure. China Journal of Drug Abuse Prevention and Treatment, No. 4, 215-219.

[14] Ersche, K.D. (2014) Paying Attention to Biased Attention in Drug Addiction. CNS Spectrums, 19, 213-214. https://doi.org/10.1017/S1092852914000170

[15] Dolezal, B.A., Chudzynski, J., Storer, T.W., Abrazado, M., Penate, J., Mooney, L., et al. (2013) Eight Weeks of Exercise Training Improves Fitness Measures in Methamphetamine-Dependent Individuals in Residential Treatment. Journal of Addiction Medicine, 7, 122. https://doi.org/10.1097/ADM.0b013e318282475e 